\title{
Interview
}

\section{Interview with Róisín Ryan-Flood}

\author{
Charlotte Beyer ${ }^{1 *}$, Róisín Ryan-Flood ${ }^{2}$
}

Published: September 10, 2019

First of all, thank you, Róisín, for generously sharing your ideas and thoughts on the subject of $21^{\text {st }}$ century feminism and lesbian motherhood.

Róisín is a Senior Lecturer in Sociology and Director of the Centre for Intimate and Sexual Citizenship (CISC) at the University of Essex. Her research interests include gender, sexuality, citizenship, kinship and migration and she has published widely in these areas. She also has a longstanding interest in feminist epistemology and methodology. Her book Lesbian Motherhood: Gender, Families and Sexual Citizenship was published by Palgrave in 2009 and remains the only monograph to explore lesbian parenting in a comparative context. She is co-editor of Silence and Secrecy in the Research Process: Feminist Reflections (Routledge, 2009) and Transnationalising Reproduction: Third Party Conception in a Globalised World (Routledge, 2018). She has been co-editor of the journal Sexualities: Studies in Culture and Society (Sage) since 2012. She is currently working on a monograph about gender and intimacy in the digital era.

Motherhood has presented feminist critics and scholars with complex questions surrounding agency and identity. In her 2013 book, Mothering Queerly, Queering Motherhood: Resisting Monomaternalism in Adoptive, Lesbian, Blended, and Polygamous Families, the critic Shelley M. Park comments on these questions, stating that,

The family is a point at which the axes of feminism, postcolonialism and queer theory frequently diverge. During the 1970s and 1980s, feminists critiqued the family as a site of patriarchal oppression. In response, women of color and critical race theorists pointed out that families of color were a critically important site of resistance to racism and colonization. As feminism began to develop more intersectional analyses of gender as inflected by race, class, nation (and other variables), more nuanced analyses of the family slowly began to emerge, resulting in what is now a prolific field of motherhood studies that provides one important (if albeit still underdeveloped) point of contact for postcolonial and feminist theorists. (Park, 2013:17)

In this Feminist Encounters special issue, we are investigating the relationship between feminism and $21^{\text {st }}$ Century motherhood. This includes examining diverse family configurations, evolving feminist positions, and discussions in relation to these important topics.

Charlotte Beyer: Róisín, I'd like to start by discussing your book on lesbian motherhood. It is a really compelling book which raises pertinent questions in relation to motherhood, parenthood and sexuality, some of which are echoed in the articles featured in this special issue.

What are the main themes and questions you investigated in your book Lesbian Motherbood: Gender, Families and Sexual Citizenship?

Róisín Ryan-Flood: The book explored the experiences of lesbians who have children after coming out, in the context of an openly lesbian lifestyle. While lesbians have always been mothers, previous generations typically became mothers in the context of a heterosexual relationship or encounter and came out subsequently. There is now a well-established 'lesbian and gay baby boom' or 'gayby boom'. My book was one of the first monographs to look at this group. I have long been interested in questions of gender, sexuality and citizenship. Lesbian motherhood seemed like an interesting topic to explore those intersections and reflected my wider interests in gender, kinship and subjectivity. When I began reading on the topic, I was struck by how many studies focused on the children in these families, treating lesbian parents as a 'needs satisfying other', in a way that completely obscured

${ }_{1}$ University of Gloucestershire, $\mathrm{UK}$

2 University of Essex, UK

*Corresponding Author: cbeyer@glos.ac.uk 
lesbian parents' own subjectivities and experiences. I was curious about how this relatively new demographic lesbians who have children after coming out - understand their experiences. How did they narrate their reproductive decision making, including choices about donors? What was it like to be a lesbian in fertility and maternity care contexts? Or at the school gate? How did lesbian parents navigate the everyday spaces of parenting? What about the experiences of couples who have children together - how is biological 'difference' understood? Was it a power imbalance in lesbian couples where one woman was the biological (and legal) mother and the other was not? How are these experiences mediated by sexual citizenship and state contexts? Finally, I was also interested in negotiations of shared care in these families and how this was navigated in same sex relationships.

The book was also the first to explore lesbian motherhood in a comparative context, drawing on my comparative research in two European countries, Sweden and Ireland. At the time they seemed to be very different in relation to LGBT rights. Sweden had a reputation for social progressiveness and was one of the first countries to introduce legal recognition of same sex partnerships in the form of registered partnerships in 1995. Yet that same legislation expressly prohibited all parenting possibilities for lesbian and gay people, including access to adoption, assisted reproduction and fostering. So you could have your relationship with your same sex partner recognised by law, but there were clear prohibitions on lesbian and gay parenting. This subsequently became a key terrain for queer equality rights and a high-profile issue in a Swedish context. In contrast, there was no public discussion of lesbian and gay parenting in Ireland or even same sex partnership rights. However, one private clinic advertised their donor insemination services to lesbian women. The invisibility of lesbian parents in Ireland meant that they were less regulated and the private sector could offer opportunities that were not available to their Swedish counterparts. Local health boards in Ireland also placed adverts for foster carers in LGBT publications. This was not because they were strong advocates of LGBT rights, but rather the chronic shortage of foster carers meant they had to expand their criteria. So, while the assumption was that lesbian parents would have an easier time in Sweden than in Ireland, the reality was more complex when you looked at the situation more closely. I was interested to see how these two contrasting social contexts affected lesbian women's reproductive choices and experiences.

I am a strong believer in and advocate of original research on queer lives in diverse geographical contexts. There is still so much that we don't know about queer histories and experiences. This is a source of constant frustration to me but also ignites my passion for my work. The lack of knowledge about so many queer lives is a reflection of its marginalisation by mainstream scholars and sends a message that queer lives don't matter, or matter less. At a time when we are seeing many positive changes in relation to sexual citizenship in many parts of the globe including in relation to lesbian parenting - it is more imperative, not less, that we document queer lives. These histories risk being lost forever if they are not recorded.

Charlotte Beyer: I think these topics and problems that you've just outlined are incredibly important. They have rarely been looked at in this way before, particular with regards to the specific Irish and Swedish case studies you examine. As a Danish woman myself, I found your discussion of Swedish lesbian motherhood and Scandinavian contexts in general really fascinating. The feminist work of documenting lives and histories is an ongoing effort, and I think you are right to highlight the need for continued effort to research and discuss sexual citizenship.

What are the shortcomings and blind spots in feminist debates around mothers and parenthood as you see them?

Róisín Ryan-Flood: Well, firstly I think there is lots of amazing work on motherhood. Much early feminist work in this field was critical of the prevailing narratives of motherhood, which implied that women should seek sole satisfaction and subjecthood through mothering. (I would argue that to a considerable extent this remains a part of popular culture discourses of motherhood today!). Understandably, feminists rejected this narrative, which obscured women's frustrations around motherhood and limited their possibilities. However, feminists also highlighted the fact that although they loved their children, they hated the constraining circumstances of maternal roles that relegated women to the home. Black feminists and others importantly highlighted the significance of motherhood in terms of community and resistance. Later feminist work also pointed out the pleasures that women derived from maternity, without idealising it. So feminist debates about motherhood have always been situated within the context and history within which they take place. It has been difficult and ground-breaking for feminists to highlight the frustrations of conventional motherhood expectations.

The second key terrain of motherhood literature concerns rights regarding reproductive control but also the conditions within which motherhood takes place. It is still the case that state subsidised childcare is far from a reality in most countries for example. Feminists are still fighting for workplaces to treat care responsibilities as something that employers should accommodate rather than assume that they should behave as if they don't have any. I think much of today's work on motherhood still addresses many of the traditional concerns about managing 
the balance of work and care. This is still seen as something that affects women more than men, because of the unequal division of care labour and because of sexist assumptions in the workplace about mothers as employees.

Both of these literatures reflect interconnecting concerns about the lived realities of parenting. I don't see this as a blind spot, but I do see it as a reflection of the fact that women have a long, long way to go to achieve equality! Here we are in 2019 and still arguing for basic rights like subsidised childcare and a degree of flexible working. The world has changed and women are now present in paid employment in ever greater numbers after having children. Yet the expectation is still that women should change, and not the workplace. It is still expected that both women and men should behave as if they are devoid of care responsibilities.

It is also the case that heterosexual women are often pitied if they do not have children, but also under pressure to conform to particular motherhood norms if they do. I would argue that openly lesbian women are under less pressure to have children. Until recently it was assumed that being lesbian meant that you wouldn't become a mother, but now that even Jodie Foster has come out as a lesbian mom it is no longer seen as a 'contradiction in terms', which is how someone described it when I told them my research topic many years ago. I think that lesbians have to both fight more to become mothers, but also face more acceptance if they choose not to, compared to heterosexual women.

The third area of motherhood literature addresses the physical realities of motherhood. Some of this work overlaps with the first two categories - breastfeeding in the workplace for example. It is still the case that women's bodies are treated as outside the norm and as problematic or offensive - witness our cultural silence around menstruation and menopause for example. Any discursive intervention that challenges that and addresses women's experiences, is therefore inherently valuable.

I particularly welcome some of the recent work on donor conception families that explores the experiences of donors, and donor conceived people and their parents. This is a fascinating field that continues to require more attention. It applies to many queer families, but not exclusively so - many heterosexual parent families are created through donor conception.

So on the one hand, I think that the emphasis on these areas in most motherhood research, is important and necessary. On the other hand, I think it would also be helpful to look beyond this in terms of social theory and empirical work. In my book, in exploring the experiences of queer mothers, I considered what it was like to inhabit a profoundly entrenched social norm in a different way. I wanted to see how they understood their experiences and came to make the choices they had. What was it like for them, to become a parent outside of heterosexuality? The experiences of minorities are always so marginalised in research and assumed to be irrelevant to everyone else, yet we have so much to learn from them. This is something that I feel very strongly about. I am currently writing a book chapter called 'Queer Lives Matter' that expands on this point - the epistemological and ontological importance of queer lives for wider social research, in a context where they are increasingly seen to matter politically on some level, but less so in social research.

Charlotte Beyer: In your book you make the compelling point that "academic research on lesbian and gay parent families has largely centred around questions of sameness and difference - to what extent these families are either 'ordinary' or 'unique"'. This point links back to the issues you touched on earlier, regarding the significance of documenting marginalised and/or unreported perspectives in relation to sexual citizenship, including lesbian motherhood.

Could you say a bit more about this issue, and the possibilities offered in your book for resisting binaries such as 'ordinary' and 'unique'?

Róisín Ryan-Flood: When I first developed an interest in this field, I was taken aback to discover that lesbian (and gay) parent families were always, always considered in terms of their relationship to so-called norms. The overwhelming emphasis in research was on the impact of their parents' sexuality on the children. This was realised in social research that emphasised the children's inherent sameness compared to their peers raised by heterosexual parents. There was a general obsession with how these children turned out - were they more likely to be gay themselves? (No). Was being a lesbian or gay person somehow incompatible with being an effective parent? (No). These questions reflect very homophobic assumptions of course about the inherent 'wrongness' of being queer and having children at all. Nonetheless, this focus on developmental outcomes for children has been really important in challenging homophobic assumptions in the courts. It used to be the case that if you came out as gay you would automatically lose custody of your children. In many parts of the world, this hasn't changed, but certainly things have improved dramatically in the UK for example. Legislative change that facilitates access to assisted reproduction by lesbians is another positive result that stems partly from this research. So while I find it frustrating that so often research has been focused on refuting homophobic assumptions, I understand that it has been necessary and believe that we owe a debt to those researchers. 
Another trend that emerged was one that emphasised positive differences. This is an important development, because for so long difference was assumed to be inherently negative in relation to these families. Stacey \& Biblarz (2001) made an important epistemological point when they highlighted how researchers assumed that any difference on the part of lesbian and gay parents would be bad, so they emphasised their overwhelming sameness to heterosexual parents and did not consider any possibility of positive differences. Yet authors highlighted how the children of lesbian and gay parents may see themselves as more open minded and aware of diversity in a positive way for example. Gill Dunne's (1998) work suggested that lesbians share childcare and domestic labour more equitably and come up with creative new ways to achieve this. These are important findings. Yet inevitably, a presentation of lesbian and gay parent families as inherently different in a positive way, just creates an essentialist norm that again not everyone will live up to. It also means that these families are judged differently and must conform to a higher standard in order to be accepted. Ultimately, any essentialist claims of good or bad parenting based solely on sexual identity - whether heterosexual or gay - is nonsense. Good and bad parents are found in every social group. Being straight or gay does not predispose you to performing better or worse parenting practices. However, homophobic assumptions suggest that heterosexuals are better parents and that queers should not parent at all. So the emphasis in theory and research on ways in which queer parents can do parenting 'well' or 'better', is understandable. It represents a challenge to constructions of a queer identity and parenting as inherently incompatible. I also think this rush to embrace positive difference, echoes what Sally R. Munt (1998) refers to as the 'pride/shame' dichotomy that haunts queer subjectivities and experience. The experience of being despised as Other means that people resist by refuting that position of shame and proclaim a positive sense of their identity. To me, this was echoed in some of the sameness/difference debates that haunt queer parenting research.

When anything is understood as 'different', it is always considered in relation to its otherness. But research that looks at these families solely in terms of the extent to which they are either the same as, or different from, a heteronormative standard (which many heterosexual parent families do not conform to either), is inevitably limiting. We have to be free to look at these families in all their complexity. To me, this is an important development that allows us to go beyond questions of how queer parents 'perform' and their children develop and opens up much more interesting questions about wider configurations of kinship, gender, normativity, queerness, and citizenship.

It is this effort to engage with questions beyond a binary opposition of sameness and difference that were at the heart of my book. So I asked about the experiences of co-parents and how differences in relation to biological parenthood were experienced and enacted within these families. How did they navigate sometimes powerful notions of inequality - for example where only one parent is recognised legally in relation to the child she raises equally from birth with her partner. I explored how social norms were experienced and engaged with within these families, through their everyday experiences.

Charlotte Beyer: The critic Shelley M. Park in her book Mothering queerly, Queering Motherhood, asks "What does it mean to mother queerly? And how might such practices [...] queer the study of motherhood?" These questions got me thinking about the symbolic and real aspects of motherhood and its representations.

Do debates around what constitutes a 'real mother' over-focus on biological aspects such as pregnancy, giving birth, breastfeeding?

Róisín Ryan-Flood: I think this is an important question. There are two things I would like to say about this. Firstly, queer theory has always emphasised transgression and challenging normativity. There is a strand of queer theory that is sceptical of what is called 'the family turn' in studies of LGBTQI lives. It sees the emphasis in research on the turn to formal recognition of same sex relationships through marriage or civil partnership and the 'gayby boom' as problematic, because it is concerned with assimilation, or homonormativity, whereby there is a new construction of the 'good gay' who is typically white, in a stable monogamous relationship and implicit in conventional modes of capitalism. While I share a critique of homonormativity, I think it is problematic to assume that all lesbian and gay parents are homonormative, or to simply assess to what extent they are or not. As I have pointed out in my work, it creates a binary between the revolutionary queer and the heteronormative mother, with lesbian moms stuck in the middle and apparently inhabiting neither space. Yet being a lesbian mother can be a profoundly queer experience. Challenging heteronormativity at every stage of becoming a parent - whether at the fertility clinic or adoption process, at the hospital, nursery and school - is a part of that experience. As a lesbian parent, you have to stand up for your family as a way of protecting your child against ridicule and homophobia directed at their family. This means coming out about your family form so that your child doesn't have to. That can certainly be experienced as a queering of everyday spaces in a productive way.

Secondly, the ability to transgress can be a signifier of privilege. In my research, this was often classed. Middle class parents were able to inhabit space as queer parents more easily, because they could be 'rich eccentrics', or access a liberal enclave through gentrification and affluence. So as I have argued in my book, queer theory is often 
unwittingly endorsing of queer privilege through the emphasis on transgression. Dismissing lesbian parents as 'not queer enough', or simply assimilating to homonormativity or heteronormative social forms, overlooks the complexities of their experiences and the constraints faced by many.

Finally, it is the case that lesbian parents are usually both queer and normative in complex ways. But rather than resort to a binary understanding of their lives, I think we need to address what their experiences reveal about wider social norms and build new theories that way. So once again, we're back to the criticism of the binary that inhabits so much work on these families. Therefore, while I welcome Parks' question about how to mother queerly, I think this cannot be the only way in which these families are of interest. Otherwise, they are set up to fail as either too assimilative and not queer enough, or acceptable only to the extent to which they performatively produce new queer relationalities that conform to a particular queer standard. Mostly, these are just parents trying to juggle care and work and raise their children in a world that is still often hostile. But this does not mean that the question of what it is to mother 'queerly' is redundant, just that it should not be the only yardstick by which these families are measured. I think in my work I highlighted many interesting and provocative moments in queering kinship that emerged from lesbian parents' narratives. So for example, lesbian parents talking about how they saw the wider gay community as a positive resource for challenging gender norms seemed profoundly queer to me.

In terms of defining motherhood, I think that on the one hand, anti-essentialist thinking - to which I subscribe! - challenges the idea that there is one way of experiencing and understanding biological motherhood. We know for example that while some women plan and welcome parenthood, many women find themselves in situations where they do not. I think that feminist work has been important in challenging normative assumptions about what a mother is and should be. In my own work, I presented cases of unplanned motherhood among my participants - a young lesbian who gave birth to a child conceived through rape, and another self-identified lesbian who had a consensual one night stand with a man and then had a child as a result. Their experiences of motherhood were affected by the unplanned nature of it, although both did bond with their children eventually. It was also the case that co-parents felt a tremendous bond and connection with the children that they had no biological or genetic tie to. This is of course unsurprising as it is something that we know from adoptive parents for example. People create family bonds with those whom they have no genetic connection. This has long been established as a queer family practice, as Weston (1991) pointed out in her classic work on 'families we choose'. But it is not exclusive to queers, as adoptive parents have long illustrated. Weston's work highlighted queer creativity in this regard - as many LGBTQI people experience rejection or distancing from their families of origin, they create new kinship communities based on love or friendship - families of choice. This notion of chosen kin has continued to be an important insight in wider family and kinship studies.

My research with Swedish lesbian parents also highlighted the history of camaraderie and kinship between lesbians and gay men. Many Swedish participants chose to co-parent with men, usually a gay male friend or couple. This reflected a wider Swedish cultural norm of participatory fatherhood, whereby men are expected to be involved parents rather than more removed breadwinners for example. This social norm became incorporated into Swedish lesbians' reproductive narratives, as they chose to have involved donors. Swedish participants often talked about the queer community as a positive resource for progressive gender norms - with men who cooked and cleaned, and women who fixed cars and did DIY. They saw this as beneficial to children, who would experience a range of positive gender role models and grow up believing that women and men did not have to conform to traditional gender norms.

Irish women were confident in their ability to create loving supportive families without involved donors. While lesbians in both countries expressed a preference for a known donor - often referring to adopted children's need to know their biological origins - they achieved this differently. So in Ireland, lesbian parents chose to have a friend or acquaintance as a donor so that they could convey his identity to a child when they were grown up, but he was rarely an involved parent and in fact often his identity was kept secret (although would be disclosed to the child when they were of age). This dramatic cross-national difference represented wider cultural norms about gender and parenting. The fact that this was realised in lesbian women's reproductive choices was a surprise to me, as nothing had been written about this before. To me, this remains an important finding because it shows how lesbians are not simply Other, but very much a product of the cultures and citizenship contexts in which they live. Too often in social theory and empirical research, queer lives are treated as interesting only in relation to their Otherness. We forget how much queers are also a product of particular cultures and societies and both inhabit and repudiate wider social norms.

Charlotte Beyer: In your book you make the powerful assertion that "lesbian mothers often occupy an uncomfortable place in academic work, torn between the pressure to be 'normal' in order to challenge homophobic critics, and the subversive imperative of queer theory." The issue of conformity in relation to sexual citizenship and lesbian motherhood still looms large, both in individual lives and on a collective level. 
Could you expand on the important point you made, regarding the "uncomfortable place" occupied by lesbian mothers?

Róisín Ryan-Flood: While there have been important changes in relation to family courts in some countries, it would be a mistake to assume that there is now full equality and that lesbian and gay parents do not face particular challenges. There is still enormous injustice and inequality in terms of ignorance that these families exist, as well as outright homophobia. Recent protests in the UK around incorporating a mild recognition that LGBT people exist in relation to sexuality and relationships education illustrates this. So work that continues to emphasise that the children within these families are no different in terms of development outcomes remains important. That is why I refuse to dismiss this work as simply a response to homophobia. It has made a difference and we owe it a debt, even though I think that the question - to what extent these children and families are the same as or different from a heteronormative family model - is problematic at best and downright homophobic and offensive at worst.

The lived experiences of these families indicate that it takes strength and courage to assert your identity and protect your child. It is not as simple as just assimilating. As I highlighted in my book, lesbian parents often went to great lengths to support their child and ensure that teachers and other parents knew about their family form so that the child did not have to 'come out' about it. A recurrent theme was having to educate well intentioned nursery and school staff about the needs of their particular families. I would say that this remains the case today. As I noted earlier, the ability to transgress is often a sign of privilege and much facilitated by particular gender, race and class identities.

Some authors have argued that lesbian and gay parenting is part of a normative impulse in society. Yet they ignore how non-normative it can feel to be a lesbian parent in daily life - at the school gate, or a playgroup for example. However, it is also the case that LGBTQI people can feel the same pull to become a parent through entrenched social norms that construct this as the most meaningful life path.

Charlotte Beyer: Your research in Lesbian Motherhood: Gender, Families and Sexual Citizenship compares and contrasts attitudes to mothering and parenting among Swedish and Irish lesbian couples.

Could you briefly outline the biggest and/or most striking distinctions and differences you identified among couples from these two countries, and the context behind those differences?

Róisín Ryan-Flood: The biggest cross-national difference definitely centred around ideas about donors and fatherhood. Lesbian parents in both countries usually preferred to have a known donor, because they thought that this would be beneficial to children. The need for some adoptive children to know their origins was often cited in support of this. In the UK, any child born through donor gametes or embryos can track down their donors when they turn 18. This is also the case in Sweden and echoes this argument about the rights of adults to know their biological heritage. It contrasts with countries like Spain, that emphasise secrecy and not disclosing a donor conception as in the best interests of the child. So the point is that these are cultural constructions, rather than pragmatic facts. The ethics around donor conception are complex and involve different sets of rights and actors donor conceived people, donors and social parents.

But while lesbian parents in Sweden and Ireland preferred a known donor, Irish women were content for him to play a donor role with no involvement. However, Swedish lesbians also expected him to be an involved parent. It was assumed that if a man donated sperm, he would also be an active father. At the time, it was not possible for lesbians to access fertility treatment, including sperm donation, in Sweden. So they had the choice to go to neighbouring Denmark for example, where it was also against the law for doctors to help lesbians with assisted reproduction. However, a Danish midwife got around a loophole in the law and was able to offer sperm donation because she was a midwife, not a doctor. So lots of lesbians from Sweden and Denmark travelled to her clinic for insemination by anonymous Danish donor sperm. One couple I interviewed from Sweden used her services, but opted to import sperm from the Sperm Bank of California (SBC), because it allowed them to use donor identity release sperm, whereby the child could access the donor's identity when they turned eighteen. This shows some of the lengths that these women had to go to in order to create their families in a hugely unsupportive political and social context. Most Swedish lesbian parents however chose to co-parent with a gay male friend or couple who was also an active father. So the children grew up with three or four parents and sets of grandparents from birth.

On a practical level, this kinship arrangement meant that these children were surrounded by extensive family networks. It was also often hugely complicated for the adults involved to navigate! For lesbians, co-parenting with gay men who they may not have known well prior to having a child together presented some difficult challenges. One participant described it as a process of becoming closer to one another over time, unlike in heterosexual parent families where the couple is the starting point. This had some advantages - more people to love and care of a child, personal growth in terms of communication - but also disadvantages. If a couple split up, then a child had to navigate moving between three or even four homes, which was difficult for the child but also the adults 
who had less contact due to more shared time. It was also the case that in Swedish law only two parents are formally recognised. So if a lesbian couple co-parented with a gay man or gay male couple, then the non-biological coparents were very vulnerable in the case of a relationship breakup or death. I interviewed women who experienced these situations and sometimes things were resolved amicably, but sometimes co-parents were marginalised and excluded and felt relatively powerless. This also relates to Butler's (2002) important question: 'Is kinship always already heterosexual?' I would argue that the construction within the law of families as only consisting of two parents reflects a heteronormative bias that overlooks the lived realities of queer families, at least in a Swedish context.

Charlotte Beyer: Your emphasis on kinship (rather than transgression) in in your book is really interesting, because it presents an alternative model for representing and thinking about parenthood.

Could you explain this idea, in light of some examples from your research?

Róisín Ryan-Flood: The fact that much prevailing work at the time focused solely on developmental outcomes for children, meant that the subjective experiences of lesbian parents themselves were often ignored or overlooked. If lesbian parents were considered, it was always in relation to how they either conformed to or challenged a heteronormative standard. I really wanted to challenge these paradigms and ask different questions about these families. This was because I felt that much of the prevailing work at the time - which was still interesting and important - unwittingly reinforced this binary of sameness and difference. To me, these were simply not what was interesting about these pioneering families. I attempted to redress this balance by asking lesbians about reproductive decision-making, experiences of co-parenting, and the everyday experiences of parenting outside of heteronormativity.

At this point, I also want to highlight how brave and innovative this group was in choosing parenthood at a time when certainly the law and wider society was profoundly unsupportive of them. It took a lot of courage to choose to parent outside of heteronormative family forms. I would argue it still does, although there is certainly a bigger infrastructure in place today and even visible role models in popular culture, which did not exist when I was doing this research.

Moving beyond the binary of transgression/assimilation meant asking different types of questions. I was interested in how lesbians inhabit a cultural norm like motherhood and navigate it in their daily lives. The fact that they were so invisible in popular culture perhaps gave them a certain freedom to be more experimental with their family formation. There was definitely a sense of this being a pioneering group. At times I was awestruck in interviews at how hard these women fought to have their families and to protect their children from homophobia and ignorance.

In focusing on their lived experiences, and how they were situated as sexual citizens, parents and lesbians, it was possible to move beyond binaries to explore the complexity of their narratives in relation to different issues. So it became evident through discourses around choosing donors for example, that lesbians are also situated within wider cultural discourses and social norms. Yet as lesbians, we are so constructed in much academic theory and research as Other, that the ways in which we inhabit (and repudiate) particular social norms is often overlooked. This is an important point, because it means that looking at queer lives teaches us about far more than queer lives! So lesbian reproductive decision making is revealing of wider cultural discourses of fatherhood for example. The fact that Swedish lesbians often chose known donors illuminates how entrenched the notion of participatory fatherhood is within Swedish culture more broadly. Too often, the expectation is that studying queer lives will only reveal insights applicable to queer lives, and that these insights are only interesting in terms of their exceptionalism. This is the reinforcement of Otherness at an epistemological level. I believe that it is important to challenge this and highlight how queer experiences reveal insights that are applicable to wider social theory and research. Otherwise, queerness just becomes ever more marginalised even while we make concrete gains in terms of social rights.

Charlotte Beyer: Shelley M. Park critiques the normative assumption that a child can only have one real mother as the assumption of what she terms 'monomaternalism'. She states that, "what is at stake in our claims about 'real' mothers is the notion that children must have one and only one mother. Heteronormative power cannot countenance polymaternal families and practices of childrearing."

This critique seems to me to chime with your work?

Róisín Ryan-Flood: Yes absolutely, I think this is an important and interesting point. As I have mentioned already, the legal framework in Sweden (and elsewhere) only recognises the possibility of two legal parents. Yet the lived reality for many of the children growing up in these families in a Swedish context (and elsewhere) was that they had three or even four parents. Dominant heterornormative discourses of kinship are centrally based around 
the 'one mother, one father' family form, even though different types of kinship - including the role of extended families - exist throughout history.

The focus on monomaternalism relates to the role of biological motherhood in culture and normative understandings of kinship. Lesbian couples who co-parented challenged this norm by having two mother figures involved in a child's life from birth. Of course this happens already with step parents for example, but I think that there is something interesting about lesbian couples who parent together because they share parenthood with another woman who is also their intimate partner. This matters, because another way in which lesbians are treated problematically in academic theory and research on these families, is that they are often studied solely in relation to their child's needs and effectively desexualised as a result. Yet their status as erotic subjects co-parenting with their lover is also meaningful. When I embarked on this research, I was curious about the experiences of co-parents - the non birth-giving mother. I anticipated that this might be a sensitive topic among couples and wondered if I should interview partners separately. What soon became apparent however, was that this was a topic that was openly discussed and acknowledged within couple relationships. This was precisely because of their presence in each other's lives as partners and lovers. So far from being a taboo topic, it was very much something that women felt comfortable being open about. This opened up a range of interesting discussions about gender, biology and parenting. The findings of course revealed that biology does not determine parenting and that bonding can take place in the absence of a biological relationship, or may take time to develop even when there is one. These complex narratives of maternity are perhaps unsurprising and echo other work on biology and kinship.

Yet what was novel was navigating this situation in a context where co-parents at that time had no legal rights. While this was not a problem when couples were happily together, it did make co-parents very vulnerable in the context of a relationship ending, or their partner dying. In addition, the biological mother was not only the legal parent, she was also more easily socially acknowledged as a mother. This was openly discussed and navigated among participants and biological mothers often asserted their support for their partner's motherhood status. Yet it remained a power imbalance. The happily egalitarian narrative that informs the transformative/subversive binary construction of these families overlooks the possibilities for inequalities that are built into these families when they are not formally recognised by law in all of their complexity.

However, I also do not think that equality is simply built around 'sameness' and it is the case that for some women, the biological relationship of motherhood was meaningful, especially when children were very young. I do not think it is necessary to ignore or denigrate those narratives of maternity, but it is important not to essentialise them and recognise the diversity of experiences. Moving beyond binaries meant exploring these women's experiences and asking difficult questions of my participants about what it means to parent with and without a genetic or biological relationship, and in the context of social and legal inequalities between partners.

Charlotte Beyer: Stories and experiences by LGBTQ+ parents and children contribute vitally to adding a sense of complexity to social constructions of motherhood, family, and community, and importantly, documenting histories of kinship.

A recent book that struck me as very interesting in this regard is the edited collection Spawning Generations: Rants and Reflections on Growing Up with LGBTQ + Parents (Demeter Press), edited by Sadie Epstein-Fine and Mazeda Zook. In the Introduction, the editors state that the purpose of the book was to, "carv[e] out a space for our voices. It is an attempt to create space for our stories without the pressures of having to conform to a narrative that demands perfection." This links with the rejection of essentialist identities which you mention, and which is so important for feminism in evolving its discourses around mothers and motherhood.

Could you say a bit about gender flexibility as a dimension of your argument to 'move beyond the binaries' which I think sounds really fruitful for feminism, and also for motherhood scholars?

Róisín Ryan-Flood: During the late '90s, there was a brief flurry of excitement in the field of queer kinship theory at the idea that lesbians and gay parents might parent differently in a positive way. So for example, Dunne (1998) argued that lesbian couples found creative ways of sharing childcare and housework more equally. This was often misinterpreted to assume that she was making an essentialist point about lesbian parenthood. In fact, she argued that some lesbian couples may be freer from some of the constraints of dichotomous gender roles and that this enables them to navigate parenting responsibilities differently. Her point about gender being played out differently in queer communities intrigued me. Ultimately all essentialist identities are ridiculous and play into the tired binary of sameness and difference, but nonetheless I think there is a lot more we need to understand about how queers do gender. So for example butch/femme relationships play out in complex ways in relation to gender that are both part of an erotic dynamic but also to do with subjectivities and identities and this is not necessarily simply an emulation of heteronormativity or part of an unequal power relationship.

I explored the question of queer genders in relation to parenting in my book. Participants usually claimed to share housework and childcare equally and that they felt it was easier to do this as women because they did not 
necessarily fall into prescribed roles, being capable at both traditionally feminine and masculine tasks for example. Swedish lesbian parents also referred to gay fathers in the same way. They highlighted that the wider queer community was a source of diversity in terms of gender performativity and felt that their children benefitted from this. Recently, the notion of queer genders is something that I find myself returning to again and hope to explore in future research on same sex couples, dating and intimacy.

Charlotte Beyer: Thank you so much, Róisín, for this really compelling discussion, and for providing so much material for further reflection and research.

\section{REFERENCES}

Biblarz, T. and Stacey, J. (2001). How) Does the Sexual Orientation of Parents Matter? Am. Soc. Rev., 66, 159. https://doi.org/10.2307/2657413

Butler, J. (2002). Is kinship always already heterosexual? Differences: A Journal of Feminist Cultural Studies, 13(1), 1444. https://doi.org/10.1215/10407391-13-1-14

Dunne, G. A. (1998). Pioneers behind our own front doors': towards greater balance in the organisation of work in partnerships. Work, Employment and Society, 12(2), 273-295. https://doi.org/10.1177/0950017098122004

Epstein-Fine, S. and Zook, M. Eds. (2018) Spawning Generations: Rants and Reflections on Growing Up with LGBTQ+ Parents. Bradford ON: Demeter Press. https://doi.org/10.2307/j.ctv157brg

Munt, S. R. (1998). Heroic desire: Lesbian identity and cultural space. New York: NYU Press.

Park, S. M. (2013). Mothering queerly, queering motherhood: Resisting monomaternalism in adoptive, lesbian, blended, and polygamous families. Albany NY: SUNY Press.

Ryan-Flood, R. (2009) Lesbian Motherhood: Gender, Families and Sexual Citizenship. Basingstoke: Palgrave. https://doi.org/10.1057/9780230234444

Ryan-Flood, R. (2018) Transnationalising Reproduction: Third Party Conception in a Globalised World. London: Routledge. https://doi.org/10.4324/9781315732695

Ryan-Flood, R. and Gill, R. (2010). Silence and Secrecy in the Research Process: Feminist Reflections. London: Routledge.

Weston, K. (1997). Families we choose: Lesbians, gays, kinship. New York: Columbia University Press.

Citation: Beyer, C. and Ryan-Flood, R. (2019). Interview with Róisín Ryan-Flood. Feminist Encounters: A Journal of Critical Studies in Culture and Politics, 3(1-2), 02. https://doi.org/10.20897/femenc/5908

Copyright (C) 2019 by Author/s and Licensed by Lectito BV, Netherlands. This is an open access article distributed under the Creative Commons Attribution License which permits unrestricted use, distribution, and reproduction in any medium, provided the original work is properly cited. 